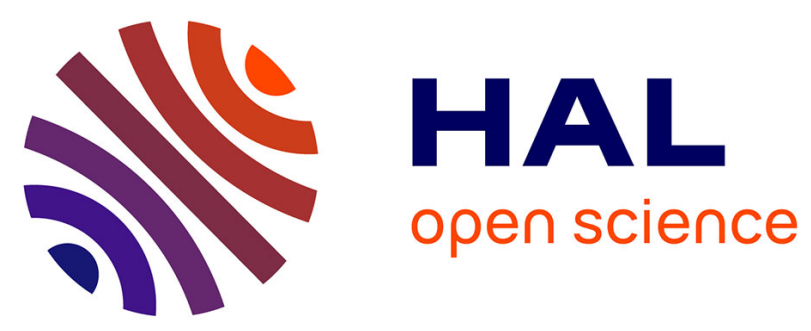

\title{
Model-Based Optimization for Robotics [TC Spotlight]
}

Katja Mombaur, Abderrahmane Kheddar, Kensuke Harada, Thomas

\author{
Buschmann, Chris Atkeson
}

\section{To cite this version:}

Katja Mombaur, Abderrahmane Kheddar, Kensuke Harada, Thomas Buschmann, Chris Atkeson. Model-Based Optimization for Robotics [TC Spotlight]. IEEE Robotics and Automation Magazine, 2014, 21 (3), pp.24-161. 10.1109/MRA.2014.2334973 . lirmm-02155303

\section{HAL Id: lirmm-02155303 https://hal-lirmm.ccsd.cnrs.fr/lirmm-02155303}

Submitted on 13 Jun 2019

HAL is a multi-disciplinary open access archive for the deposit and dissemination of scientific research documents, whether they are published or not. The documents may come from teaching and research institutions in France or abroad, or from public or private research centers.
L'archive ouverte pluridisciplinaire HAL, est destinée au dépôt et à la diffusion de documents scientifiques de niveau recherche, publiés ou non, émanant des établissements d'enseignement et de recherche français ou étrangers, des laboratoires publics ou privés. 


\section{Model-Based Optimization for Robotics}

By Katja Mombaur, Abderrahmane Kheddar, Kensuke Harada, Thomas Buschmann, and Chris Atkeson

N ature has demonstrated an incredible ability to optimize the designs and behaviors of humans, animals, and plants. Many areas of engineering have tried to copy the optimality principles of nature or optimize technical properties of systems, and mathematical optimization has been a very helpful tool in this context.

To promote the use of optimization methods in robotics, the IEEE Robotics and Automation Society (RAS) Technical Committee (TC) on Mod-

The vision of this IEEE

RAS TC is to promote

the research and

education on this

aspect as part of the

efforts to provide

better services to

society. el-Based Optimization for Robotics was founded and approved by the IEEE RAS Technical Activities Board and the RAS Administrative Committee in October 2012 with Cochairs Katja Mombaur, Abderrahmane Kheddar, Kensuke Harada, Thomas Buschmann, and Chris Atkeson. The TC focuses on optimization in robotics in the very general sense and, in particular, on the development and application of optimization methods for the design of robots and the generation and control of dynamic behaviors in robotics as well

Digital Object Identifier 10.1109/MRA.2014.2334973 Date of publication: 10 September 2014 as their practical implementation. Optimization approaches are, in principle, applicable to any type of robot or robot behavior but are most interesting for robots with complex structures and dynamics, e.g., humanoid robots, or for high speeds, e.g., in mobile or agile manipulation (Figures 1-3). Optimization problems in robotics range from different tasks related to model identification (such as parameter estimation, optimum experimental design, inverse optimal control, and so on) over design optimization to optimal behavior generation (offline optimal control, model predictive control/online optimal control). Recent developments in optimization algorithms and, in particular, real-time optimization make a wider application of algorithmic optimization a realistic option even for real-time control in complex robotic applications in the near future.

There is a growing interest in optimization in the robotics community for behavior generation and control, as recent publications and workshops show. However, it can be observed that the level of optimization techniques used is often far behind the current state of the art within the optimization community and that only very simple optimization problems are solved. This prevents the optimization potential of existing robot platforms from being fully exploited, and current designs are often suboptimal. But some papers show very interesting optimization solutions for the most advanced robotic systems, even for complex tasks with impacts or varying constraints, such as weight lifting or fast walking. At the same time, it is still a major challenge to actually apply these optimal solutions robustly to real robots and to handle modeling errors and uncertainties.

Important research areas in the scope of this TC include:

- the optimization-based generation of robot trajectories using dynamical models of the robot and its environment

- improving the behavior style of robots by optimization, in particular for humanoid robots (induce natural behavior)

- online motion control using realtime model-based optimization and model predictive control/receding horizon control

- optimizing the design of robots for given tasks (parameter optimization and structural optimization)

- the development of appropriate dynamical models for offline and online optimization

- learning/improving models during optimization

- inverse optimal control techniques for the identification of objective functions

- robust optimal control and the refinement of optimal control policies based on actual experience

- the combination of optimization and machine-learning approaches

- the combination of optimization and path-planning methods.

\section{TC Activities}

Since its foundation in late 2012, the following activities have been pursued 


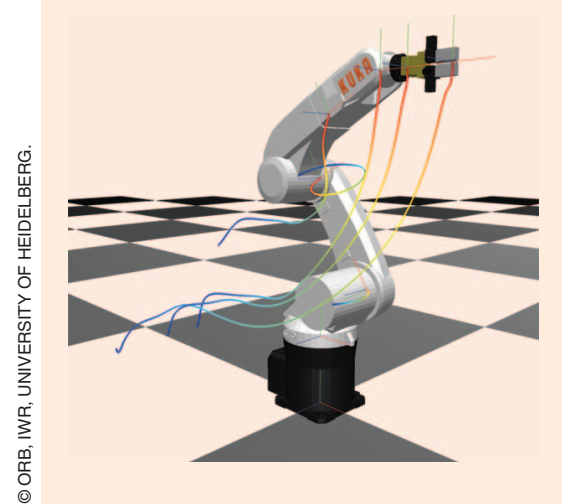

Figure 1. Optimal trajectories for a KUKA KRsixx R850 robot.

by the TC on Model-Based Optimization in Robotics.

\section{Workshop Organization}

- Workshop on Generating Optimal Paths in Humanoid and Industrial
Robotics at IEEE-RAS Humanoids 2012 (Osaka, Japan, November 2012)

- Workshop on Novel Methods for Learning and Optimization of Control Policies and Trajectories for Robotics at the IEEE International Conference on Robotics and Automation 2013 (Karlsruhe, Germany, May 2013)

- Workshop on Inverse Optimal Control and Robot Learning by Demonstration at Robotics: Science and Systems (RSS) 2013 (Berlin, Germany, June 2013)

- Workshop on Physical Assistive Devices: Model-Based Simulation and Optimization at IEEE/Robotics Society of Japan (RSJ) International Conference on Intelligent Robots and Systems (IROS) 2013 (Tokyo, Japan, November 2013)
- Workshop on Online and Offline Optimization for Humanoid Robots at IEEE/RSJ IROS 2013 (Tokyo, Japan, November 2013)

- Workshop on Optimization Techniques for Motion Generation in Robotics at RSS 2014 (Berkeley, United States, July 2014).

\section{Tutorial Organization}

- Heidelberg Collaboratory for Industrial Optimization (HCO) Workshop on Industrial Optimization-A tutorial workshop on nonlinear optimization and optimal control for participants from industry and academia, with optimization in robotics as a subtopic (Heidelberg, Germany, February 2014).

(continued on p. 161)
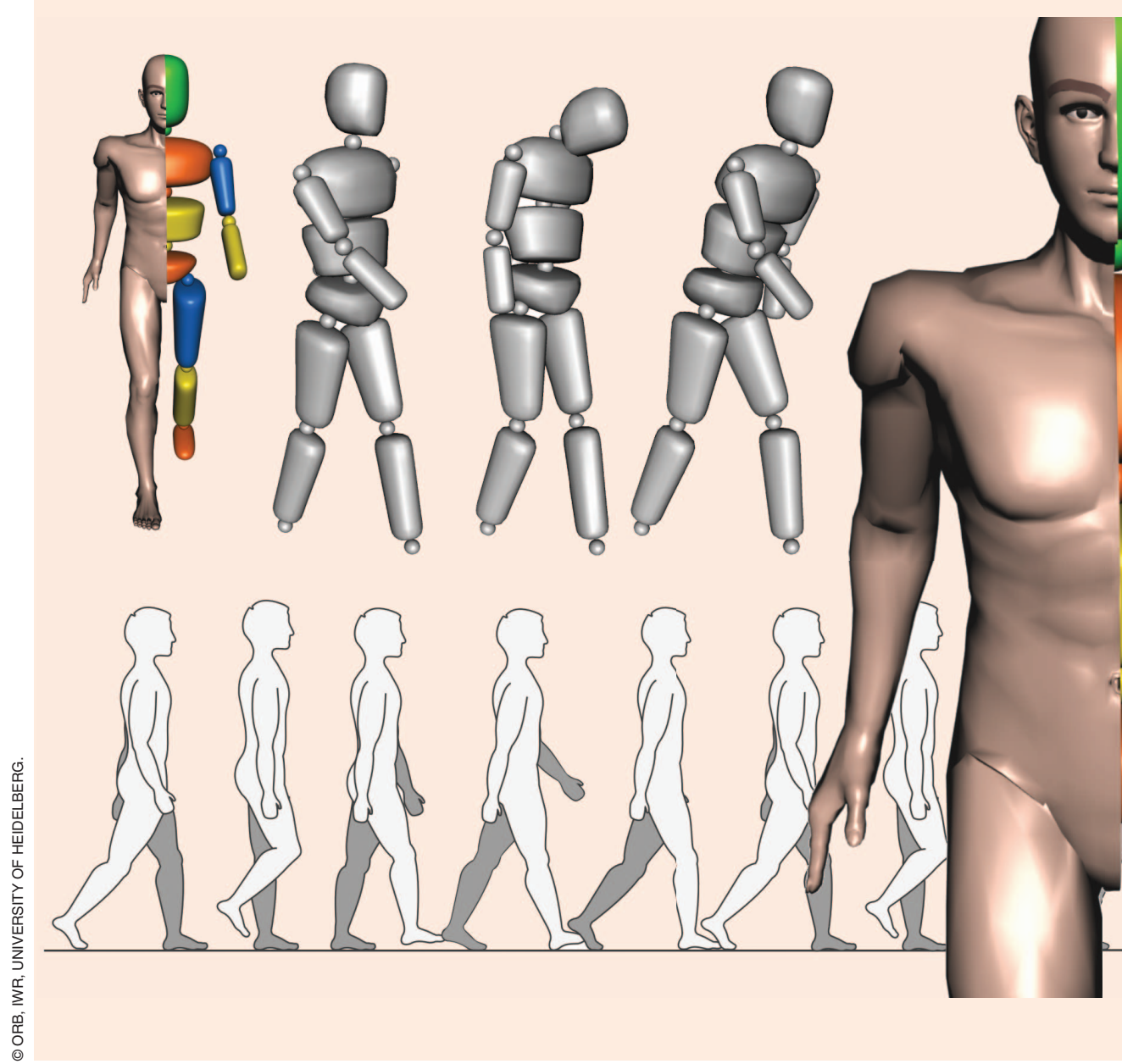

Figure 2. The generation of humanlike walking motions under different emotions by model-based optimization. 


\section{Encourage Collaboration}

and Leverage "Hive Mind"

Teamwork is fundamental for a leader.

Being a leader is not just about you; it is about the people around you that you lead, and it is about giving them power-positive power. As a leader, it is necessary to work as a sponsor of team members to be more than a mentor to give them opportunities to grow and realize their projects.

There is no formula for becoming a leader. You have to embrace what is unique and different about you. These qualities can foster diversity and innovation.

The IEEE WIE, with its events and activities, is a great channel to inspire, engage, and advance women in engineering, to share experiences of success and career growth in the industrial and academic fields to convey important lessons from women to other women and men.

\section{TC SPOTLIGHT (continued from p. 25)}

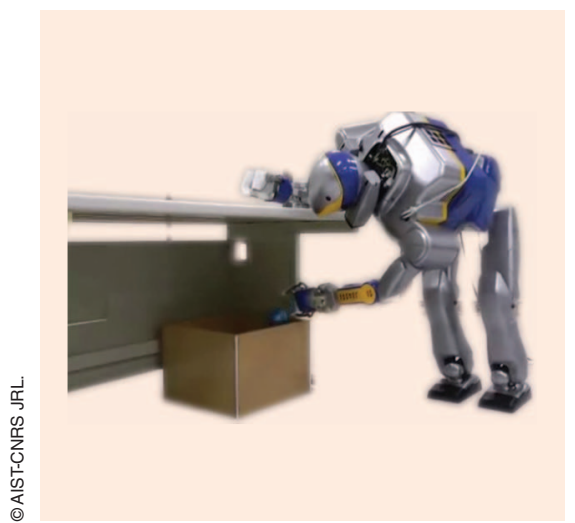

Figure 3. Optimal whole-body reaching motions with multiple contacts for the humanoid robot HRP-2.

\section{Outreach Activities Outside the RAS}

Several activities aim to bridge the gap between the mathematical optimization and the robotics communities via activities at major mathematical optimization and scientific computing conferences.

A minisymposium on modelbased optimization in robotics will be organized at the High Performance Scientific Computing Conference in Hanoi, Vietnam, in March 2015, which has a strong focus on optimization.
Two keynote presentations at major mathematical optimization conferences (the French-German-Polish Conference on Optimization and the European Conference on Computational Optimization) advertising robotics applications and the TC have been delivered.

Members of the TC can receive regular information via the TC's Web site and a newly established newsletter and can engage in scientific discussions. If you wish to join the TC, please send an e-mail to Katja Mombaur(kmombaur@ uni-hd.de) or join via our Web page at www.tc-opt.uni-hd.de.

\section{moving?}

You don't want to miss any issue of this magazine!

\section{change your address}

BY E-MAIL: address-change@ieee.org

BY PHONE: +1800678 IEEE (4333) in the U.S.A. or +17329810060 outside the U.S.A.

ONLINE: www.ieee.org, click on quick links, change contact info

BY FAX: +1 7325625445

Be sure to have your member number available. 